\title{
LA IDEA DEL “INDIO” EN CHIAPAS, 1794-1821
}

\author{
Amanda Úrsula Torres-Freyermuth
}

Resumen: Este artículo seenfonca en el análisis del discurso creado en torno a la figura del "indio" chiapaneco desdefinales del siglo XVIII hasta 1821. El propósito es enfatizar el modo en que era visto el indio así como las políticas que se adoptaron respecto a él en una época de ebullición política y social. Se pretende entender cómo pensaban y actuaban los grupos de poder frente a esta población dilucidando su concepción del indio, lo que ayudará a explicar mejor las condiciones de vida de este sujeto en una coyuntura de transición.

Palabras clave: indígena, cultura política, discurso.

Enviado a dictamen: 28 de junio de 2012

Aprobación: 30 de julio de 2012

Revisiones: 2

Mtra. Amanda Úrsula Torres Freyermuth, maestra en Historia Moderna y Contemporánea por el Instituto Dr. José María Luis Mora, actualmente doctorante en el Posgrado de Humanidades de la Universidad Autónoma Metropolitana, unidad Iztapalapa. Temas de especialización: historia política y social de Chiapas, estudio de la cultura política siglo XIX, historia legislativa siglo XIX. Correo electrónico: amanda_ursulat@hotmail.com.
Abstract: This article focuses on analyzing the discourse created around the concept of "Indian" in Chiapas in the late eighteenth century to 1821. The purpose is to emphasize how he looked, and the policies adopted towards him in a time of social and political ferment. It seeks to understand how they thought and acted powerful groups against this population elucidating his conception of the Indian, which will help to explain better the lives of this subject at the juncture of transition.

Keywords: indigenous, political culture, discourse.

\section{Introducción}

$\mathrm{E}$ concepto de indio o indígena americano, como bien sabemos, es producto de una invención histórica occidental que tuvo su origen en la conquista de América (O’Gorman, 1995). Esta invención se ha ido transformando con el paso de los años y aún hoy en día sigue actualizándose.

Ha sido de mi interés desde hace varios años el estudio del indígena chiapaneco en la transición de la colonia a la vida independiente. Me he enfocado al estudio de la desaparición de esta figura jurídica a partir del liberalismo gaditano, que consecuentemente dio fin a la propiedad comunal de la tierra y a las llamadas repúblicas de indios, lo que implicó no sólo que los 
individuos que las componían accedieran a derechos políticos, sino que desapareciera de un plumazo la institución y tenencia de la tierra que habían asegurado su privilegio.

Esta desaparición jurídica obliga a preguntarse cómo se dio ese cambio en un espacio como el mexicano, y en Chiapas específicamente. Provincia única por sus características: rica en recursos naturales y humanos, atrasada económicamente, pero, sobre todo, eminentemente indígena. Chiapas era, y sigue siendo, india. Para 1814 había en Chiapas 20 indios por cada español. Un censo de la época muestra que la población india constaba de 105,252 individuos, y la mestiza de 21,507 (entre la que se contabilizaba a la población negra); como contraparte, la pequeña población española estaba constituida por sólo 3,539 personas, siendo el total de la población de 130. Este artículo se enfoca en el analisis del discurso creado en torno a la figura del "indio" chiapaneco desde finales del siglo XVIII hasta la primera república federal (1825-1835).

El propósito es enfatizar el modo en que se le veía así como las políticas que se adoptaron respecto a él en una época de ebullición y de transición política y social. Por ello, iniciaremos viendo al indio en Chiapas y Guatemala a finales del siglo XVIII; posteriormente trataremos la percepción que de él prevaleció en las Cortes de Cádiz (1810-1814), las medidas tomadas para cambiar su estatuto jurídico y la participación de los diputados chiapanecos en ello; finalmente analizaremos los textos que vieron la luz entre 1814 y 1821.

Se pretende entender cómo pensaban y actuaban los grupos de poder frente a la población indígena dilucidar su concepción del indígena, lo que ayudará a explicarnos mejor las condiciones de vida de este sujeto en la coyuntura de transición chiapaneca. Ello a partir del estudio de la cultura política que prevaleció en torno a este sujeto durante el periodo de transición del antiguo régimen - la colonia - a la independencia, entendiendo la cultura política como el conjunto de ideas, valores, creencias, actitudes, discursos y prácticas compartidas por un grupo determinado y que tienen como producto fenómenos políticos.

La cultura política a analizar es la de la élite, que definió los temas del debate político, condujo en una dirección u otra a la opinión pública y tomó decisiones que incidieron en la estructura del sistema político chiapaneco. Este estrato social pretendió, en el tránsito del antiguo régimen a la "modernidad política", difundir las formas de sociabilidad moderna que ponían en el centro al ciudadano, colocando el acento en el individuo, valor supremo y que sustituiría a las corporaciones.

El indígena chiapaneco ha sido objeto de estudio de múltiples historiadores e historiadoras, sobre todo para el periodo colonial, como Jan de Vos, Antonio García de León, Juan Pedro Viqueira y Gudrun Lenkersdorf. También se han estudiado los periodos posteriores a la segunda mitad del siglo XIX desde diferentes aspectos: la religión, el ejido, el consumo de aguardiente, la justicia y la guerra de castas de 1869.

Sin embargo, el periodo de este estudio solamente ha sido examinado en Vivir en frontera de Jan de Vos y en Resistenciay utopía de Antonio García de León. La primera obra constituye la reconstrucción de la "frontera india" y del "lento despertar indígena" en tres siglos de historia a partir de fuentes de primera mano que introducen al lector en las estrategias de resistencia y negociación de los indios frente a las clases gobernantes. El texto de García de León, por su parte, muestra la historia de la lucha social en Chiapas desde la conquista hasta finales del cardenismo a través del estudio de la concentración de tierras y riqueza por un grupo oligárquico - "la familia chiapaneca"- y de la explotación del trabajo indígena. Ambos estudios, de larga duración, muestran el despojo y la explotación que los indios vivieron bajo la opresión de los grupos de poder de la provincia.

A diferencia de estos estudios, que han analizado la historia del indígena chiapaneco, el objetivo de este texto es entender qué pensaban las élites de poder de la gran población india, es decir, de qué manera lo fueron 
"inventando" en los últimos años del siglo XVIII y en las primeras dos décadas del XIX. Lamentablemente, no podemos conocer de qué forma la población autóctona se "inventó" a sí misma dado que hasta el momento no hemos encontrado fuentes al respecto.

\section{El indio y la Ilustración en Chiapas y Guatemala: en vísperas del constitucionalismo gaditano}

En 1794 se creó la Sociedad Económica de Amigos del País en Guatemala gracias a la iniciativa de Jacobo de Villaurrutia. Dicha corporación tenía como propósitos principales el fomento de la agricultura, la industria, los oficios y las artes, mejorar la educación pública, acabar con el ocio de la población y generar nuevos modos de subsistencia (Bonilla, 1999: 118).

La Sociedad de Amigos de Guatemala y la Gaceta de Guatemala, que se publicó semanalmente a partir de 1797, difundieron y promovieron las ideas de la ilustración. Para la Gaceta, la economía política era un asunto de gran importancia, por ello se debatieron allí diversidad de temas, promoviendo nuevas ideas y denostando todo aquello que significara el estancamiento en el pasado (Rodríguez, 1984: 38).

Entre los temas que a la economía política concernían destacaba el "problema del indio" dada la gran población indígena presente en el territorio (Rodríguez, 1984: 41). Coexistían dos visiones del indígena entre los ilustrados de la época: la que los veía como "haraganes, que no trabajan si no se les obliga", y la que los consideraba "inclinados al vicio, especialmente a la embriaguez, y que aumentan entre ellos las borracheras y los escándalos si no se les tiene ocupados con el trabajo obligatorio" (Martínez, 1998: 171); es decir, eran considerados como los causantes del atraso del reino. El que el indio fuera "por naturaleza" flojo, implicaba que no trabajaría aunque el salario que se le otorgara fuera mejor $y$, en el caso de hacerlo, se gastaría toda la ganancia en bebida (Bonilla, 1999: 144; Martínez, 1998: 173).
Un documento que refleja está visión es el Informe que da el Gobernador Intendente de Chiapa del Miserable estado que se hallan a la presente, los Partidos de la Intendencia de su Cargo, Y propone al mismo tiempo, los remedios y auxilios que pueden subministrársele para su incremento y beneficios, escrito por Agustín de las Queratas y Zayes. ${ }^{1}$ En este documento el intendente de Chiapas presentaba un balance de la situación de la provincia desde que las alcaldías mayores fueron suprimidas con la implantación del sistema de intendencias y exponía un panorama desalentador. De entrada, explicaba, la capital de la provincia se encontraba en ruinas y era de suma dificultad poner en marcha obras públicas debido a que la única entrada de capital a la hacienda pública era la proveniente del tributo indígena, la mayoría de las veces pagada con "los efectos del país" y pensaba que llegaría "el caso de no poderlo hacer de otra manera". Para el intendente, los indios "siembran los frutos que les produce el país que por lo común son de muy baja estimación. Asisten por los jornales a los servicios personales y con harta fatiga alcanzan lo necesario para mantenerse y vestir miserablemente".

La crisis asolaba a todos los sectores de la intendencia: los hacendados, "a mas de estar pensionadas sus heredades con muchos capitales de capellanía y obras pías", padecían graves problemas económicos por la mortandad del ganado-causada por la escasez de agua. Los pequeños agricultores estaban "tan atrasados" que se veían en la necesidad de vender sus productos a precios menores de los del mercado: "apenas se costean viéndose obligados a mal vender sus frutos, y muchas veces se han quedado con ellos apolillados por el poco expendio que tienen". Los comerciantes obtenían muy pocas ganancias de sus negocios porque al comprar "los efectos mercantiles hasta de cuarta y quinta mano se les agregan los derechos de alcabala".

Para el intendente el escenario era desolador: "han llegado a decaer estos partidos tanto que ya los miro casi arruinados y llenos de miseria”. ¿A qué se debía el infortunio que se vivía en Chiapas? A la supresión del 
sistema de repartimiento de mercancías que ponían en marcha los alcaldes mayores, quienes obtenían fondos con los que "habilitaban a los pueblos, haciendas de cacao, cría de grana, siembras de algodón, fábrica de petates, mantas, naguas y otras manufacturas proveyendo a los indios no sólo de reales a su auxilio, sino de las herramientas necesarias y demás útiles para sus faenas". Además de proporcionar el capital para la producción de artículos y de productos agrícolas, los alcaldes obligaban a la población nativa a laborar, ya que los indios eran considerados:

[...] individuos que solo se contentan con lo preciso para adquirir el sustento. Es el indio un animal de costumbres que propiamente puede colocarse entre el mono y el hombre, pues se le observan acciones muy [similares] a las dos especies: nada hace si no se le manda por el juez, o el padre cura, pues como se contenta con poco y nada ambiciona no le motiva a trabajar el deseo de tener bajo este axioma comprobado con la experiencia es indispensable teniendo a la vista su inclinación ver el modo de aplicarle un agente que mueva a su maquina, aunque sea solamente a ejercitarlo en aquello que le manden ${ }^{2}$

El informe de Agustín de las Queratas y Zayes concluía que "en lugar de hacer feliz esta provincia con el establecimiento de un intendente, cajas reales y demás empleados [...] ha resultado su ruina".

La misma visión negativa puede encontrarse quince años después, ya iniciado el siglo XIX, en el Informe del ayuntamiento de Ciudad Real sobre "los obstáculos que retardan en estas provincias el progreso de la agricultura", a pesar de la gran riqueza que caracterizaba al territorio, así reconocida por los miembros del ayuntamiento: "pues la fertilidad de estos terrenos es tanta que sin tener el cultivo necesario produce muchas plantas, y hierbas vistísimas", así como su localización geográfica favorable con gran potencial comercial. ${ }^{3}$
El panorama era "más digno de lágrimas que de ponderación, y por más que se exagere, nunca se podrá hacer una pintura al vivo del miserable estado tan deplorable en que se hallan los naturales del País". La agricultura y el comercio no progresaban porque los operarios y jornaleros indígenas estaban generalmente "enajenados en los vicios del ocio y embriaguez", por lo que mientras no se desterraran esos vicios no se conseguirían los aumentos deseados.

Esta percepción de la población indígena estaba íntimamente ligada al lugar que tenía en la sociedad: el indio era "el trabajador de la tierra"; el sujeto que laboraba para el hacendado, el rey, el clero y su comunidad. Esto se debía a los derechos y obligaciones que lo hacían un "sujeto especial" en las Leyes de Indias. El indio "está allí para servir"; para el criollo "el indio es y debe ser el complemento de la tierra" (Martínez, 1998: 199). Además, tanto la postura del intendente como del ayuntamiento permiten vislumbrar lo importante que era la mano de obra indígena para la provincia: las haciendas requerían de ella y las finanzas públicas dependían básicamente del tributo.

La visión opuesta fue expresada por el grupo de ilustrados que abogó por la abolición del repartimiento de indios para que fueran insertados en el sistema de trabajo asalariado, afirmando que cuando se les pagara justamente por su trabajo lo realizarían sin necesidad de sujeción. Esta corriente la encabezaba José Antonio Liendo y Goicochea, y formaban parte de ella José María Peinado, José Aycinena, Matías de Córdova, Antonio Juarro y José del Valle. Todos ellos se esmeraron en sus escritos por "demoler [algunos de] los prejuicios raciales existentes” (Bonilla, 1999: 149).

Un texto que puede ilustrar esta postura es el escrito en la década de los cuarenta del siglo XVIII y publicado en 1789 por José Campillo y Cosío, titulado Nuevo sistema de gobierno económico para la América, indispensable para defender tal posición. Campillo rechazaba el supuesto de que la vida precaria que llevaban los indígenas fuera causada por su inferioridad racial o su holgazanería. 
Para él, el atraso no era atribuible al indio per se sino a la mala organización del cultivo de las tierras y de la mano de obra, así como a la estratificación de la sociedad que los había "reducido a la barbarie".

En el supuesto de que los indios tuvieran el potencial intelectual tan limitado como se decía, aseguraba que era aún mejor, pues le parecía que: ["la circunstancia más feliz que puede haber para los fines políticos; pues de este modo se podrá con toda facilidad hacer de ellos aquello lo que se quiera, habiendo hombres que sepan $y$ alcancen oportunamente valerse de esta ventaja para dirigirlos al bien suyo y del Estado, que es únicamente lo que proponemos, promovemos y tratamos" (Campillo, 1789: 90)]. Los indios trabajarían en lo que se les mandara estarían dispuestos a obedecer.

Una vez encaminados al trabajo, aseguraba, si se les dejaran los frutos de su esfuerzo se convertirían en un sector económico de suma importancia. Por ello, era indispensable que se les dieran tierras en propiedad para hacerlas útiles y reactivar la economía a través de la agricultura.

Esta misma percepción se manifiesta en un ensayo escrito por Fray Matías de Córdova para un concurso convocado por la Real Sociedad Económica en el año 1796. Su texto sobre "el problema del indio" tiene el propósito de mostrar que el indio actuaba de acuerdo a su propio interés dado que no era consumidor de artículos como el calzado y el vestido y trabajaba sólo para el autoconsumo sin necesidad de producir un excedente que le permitiera adquirir otros bienes: "únicamente necesitando los indios y mulatos de vestirse, y calzarse, se excitarán del ocio, gozarán de una vida cómoda, asegurarán su felicidad, necesitando los unos de los otros, que es lo que hace el hombre sociable". ${ }^{4}$

Córdova partió del hecho de que los indios se hallaban en estado de ociosidad e ignorancia por la falta de necesidad de trabajo que los caracterizaba: "No aguardemos, pues, prudencia ni racionalidad en los indios, mientras se hallen apoderados del ocio; ni creamos que éste se aniquile hasta que les sea preciso trabajar, esto es, hasta que necesiten de vestir". Por ello, señaló la importancia de que los indios tuvieran las mismas necesidades de la población ladina, ${ }^{5}$ pues de esta manera se convertirían en consumidores de las mercancías a las que el resto de la sociedad tenía acceso. Así se integrarían adoptando las costumbres de "los hombres de superior jerarquía":

Si éste estuviere vestido como los españoles, siendo natural la imitación, aprendería sus costumbres, y cotejando la sinceridad, la honestidad, la suavidad en el trato y el deseo de complacer, con la doblez, el descaro, la grosería y el egoísmo, no podría menos que avergonzarse y emprendería estas virtudes, aunque no fuera más que por preciarse de hombre culto. ${ }^{6}$

El texto de Matías de Córdova contribuyó, como afirma José María Portillo, a "forjar una línea divisoria entre progreso y atraso" según la cual la asimilación se vinculaba al progreso mientras que la resistencia a la misma se reputaba como enemiga "de la civilización y el comercio, valores esenciales del progreso" (Portillo, 2006: 214). La civilización se manifestaba en la forma de vestir del individuo, mientras que la escasez de calzado y la desnudez eran un reflejo de la tendencia a la perversión social y de la incivilidad.

Otro documento que respaldaba el proyecto de asimilación de Matías de Córdova fue el titulado Apuntamientos sobre agricultura y comercio del Reino de Guatemala, redactado en 1810 por el Real Consulado de Comerciantes de Guatemala para la representación del diputado a Cortes Antonio de Larrazábal. El texto es interesante pues en él fueron plasmadas las ideas económicas que tuvieron mayor peso en la época para las élites locales. El consulado veía a los indígenas de la época como una continuidad de sus antepasados, pues le parecía que seguían conservando la misma vida que antes de la colonia y que eran individuos "adictos a 
sus costumbres y usos antiguos". Se dedicaban a una agricultura precaria pues no conocían el "refinamiento" de las civilizaciones "cultas". Sin embargo, tal "atraso" en su agricultura no significaba que el indio representara un sector ocioso de la sociedad; al contrario, todos los indígenas mayores de edad eran enviados por el sistema de repartimiento a las haciendas y a las obras públicas haciendo el trabajo "penoso y molesto". Para el consulado, los indios eran una clase productiva: "ellos son el descanso de las demás clases sin exclusión; ellos son los que nos alimentan surtiéndonos de lo necesario y de regalo, al paso que ellos son tan parcos y frugales que casi nada comen de sustancia" (Bonilla, 1999: 199-201).

Para subsanar la penosa situación del indígena, el texto recomendaba la formación de una Junta Protectora del indio integrada por varios administrativos coloniales de importancia que tendría varias funciones, entre las que destacaba el reparto de las tierras propias de las comunidades a los indígenas varones en edad de casamiento. Estas tierras se darían en "absoluta propiedad para sí y sus sucesores" sin la posibilidad de ser desposeídos de ellas por parte de "sus justicias". Aunque estos terrenos se otorgarían en propiedad a los cabezas de familia, no podrían responder como pago de las deudas adquiridas por el "propietario", pues seguirían perteneciendo "al ejido del pueblo".

El indio tendría, con esta propiedad, plena libertad de pagar el tributo en moneda o con lo que hubiera cosechado en su "sementera"; asimismo, podría vender sus productos y comprar otros que necesitara de acuerdo a los precios del mercado. Se convertiría así en un propietario más, listo para participar en las nuevas formas de organización de la economía que estaban gestando en el mundo occidental. En el texto no se estipulaba la fragmentación de las tierras comunales ya que, a pesar de que se contemplaba su división para ser entregadas a los indios cabeza de familia, estos terrenos se seguirían concibiendo como parte del ejido. Se empezaba así a romper con la visión tradicional del indio como parte de una corporación para concebirlo como ente individual productivo, a diferencia de aquella en la que se manifestaba una actitud negativa hacia la población indígena.

Por lo que se ha visto, para el intendente Queratas y Zayes de Chiapas y para los miembros del ayuntamiento de Ciudad Real, concretamente, el indio era una especie de animal entre humano y simio que debía ser forzado al trabajo pues no tenía la capacidad racional suficiente para comprender lo que le convenía: eran viciosos y ebrios, y por lo tanto necesitaban de sujeción para ponerse activos.

En cambio, para los ilustrados, aunque el indio era perezoso y atrasado, podía cambiar porque era un individuo con capacidad racional suficiente. Se necesitaba impulsarlo al cambio, lo que implicaba dejar atrás sus costumbres, su lengua, su vestido y su comunidad. Era hora de ser asimilado a la sociedad, de convertirse en un consumidor más y en un nuevo propietario.

El indígena bueno era aquél que dejaba de serlo. Lo que se proponía concretamente el proyecto ilustrado era su exterminio cultural. Sólo cuando el indio dejara de lado sus costumbres adoptando las de los españoles, cuando fuera asimilado culturalmente, podría ser integrado a la sociedad. ${ }^{8}$

\section{El “indigenismo" en las Cortes de Cádiz}

El largo proceso que culminó en la crisis española de 1808 producto de la invasión de la península Ibérica por Napoleón Bonaparte y la abdicación de la familia real a la corona, a resultas del supuesto secuestro del "deseado" Fernando VII, tuvo como consecuencia un cambio en la forma de concebir las instituciones políticas, los territorios ultramarinos y la constitución social del imperio español.

Se encontró la península sin una cabeza soberana de gobierno. A lo largo y ancho de ésta se formaron juntas de gobierno en las provincias, las cuales se autoerigieron como depositarias de la soberanía del 
rey. Posteriormente, se formó una Junta Central que fue reconocida por todas las anteriores como la cabeza dirigente. Lamentablemente, bajo su mando el enemigo ganaba terreno y su autoridad se veía cada día más deslegitimada, de ahí que en el año 1810 resolviera convocar a Cortes. ${ }^{9}$

Los representantes de las diferentes provincias españolas y americanas se reunieron en las Cortes en septiembre de 1810 con la finalidad de ejercer la soberanía que hasta ese momento había sido atributo de la Regencia. En esta asamblea se debatieron temas de diversa índole, cruciales para llevar a buen cauce "la reforma de las antiguas leyes de la monarquía" que habían sido pervertidas. ${ }^{10}$

Entre ellos se debatió la problemática indígena, sobre todo cuando se trató de determinar la representación en las Cortes. En este sentido, los diputados americanos pedían que se incluyera a los indígenas y a las castas en la base de población representable para que sus provincias tuvieran un número mayor de representantes, basándose en el decreto de las Cortes del 15 de octubre de 1810 en el que se afirmaba que "los dominios españoles en ambos hemisferios forman una sola y misma monarquía, una misma y sola nación, y una sola familia" y por lo tanto "los naturales que sean originarios de dichos dominios [...] son iguales en derechos a los de la península"."

Por su lado, los diputados peninsulares rechazaban esta inclusión para mantener la superioridad numérica, afirmando que el indígena estaba imposibilitado para ejercer la ciudadanía dado que:

[...] es tal la pequeñez de su espíritu, su cortedad de ingenio, su propensión al ocio [...] que al cabo de tres siglos de oportunas y empeñadas providencias para entrarlos en las ideas comunes y regulares se muestran iguales a los del tiempo del descubrimiento de las Indias. En el singular y laudable propósito de conservarlos en su pureza de origen y de atemperarse en lo posible a usos y costumbres, la ley los estima en la capacidad de aun menos de siete años y les concede de lleno un cúmulo de exenciones y privilegios que no tienen ejemplar (Rieu-Millan, 1990: 108). ${ }^{12}$

¿A qué se debían estas aseveraciones de los diputados peninsulares? Hasta ese momento el indio había tenido "el status inferior en la familia" (Clavero, 1994: 12). Su posición estaba determinada por los tres estados en que se encontraba clasificado: rústico, persona miserable y menor. La rusticidad era dada por su falta de cultura letrada, sus costumbres su estado de aislamiento, marginación exclusión y desentendimiento. Era miserable debido a su incapacidad para valerse socialmente por sí mismo, atenido siempre a una intercesión particular.

Rusticidad y miseria eran status con un tratamiento propio, con privilegia. Igual a estos era el estado de minoría. Todos los indígenas eran juzgados menores partiendo de la consideración de que no eran "gente de razón". Esta minoría determinaba la sujeción del indio a una patria potestad (Clavero, 1994: 14; Clavero, 2000: 85)

Fue por ello que los diputados americanos se encontraron frente a la ardua tarea de comprobar que la población indígena en América era capaz de gobernarse a sí misma, que era trabajadora y racional. Uno de los primeros intentos al respecto fue el de la representación de los diputados del reino de Guatemala con varias solicitudes a las Cortes, una de las cuales era que las llamadas cajas de comunidad fuesen empleadas exclusivamente para el bien de ésta y para la "utilidad de los indios y socorro de sus necesidades". Lo interesante de este documento es la manera en que los diputados se expresan acerca del indio:

[...] con especialidad acerca de los indios pues conocemos ser una de nuestras primeras obligaciones procurar la felicidad y bien de aquellos infelices a quienes tanto debemos cuyas tierras poseemos, y ellos son usando de las expresiones del Excelentísimo e Ilustrísimo Señor Don Juan de Palafox virrey de Nueva España los pobres que 
nos enriquecen, los desnudos que nos visten y hambrientos que nos alimentan. ${ }^{13}$

Reconocer el trabajo de los indios, así como su importancia en la economía del reino, era el primer paso para impulsar que fuesen considerados iguales a los españoles. Para respaldar sus argumentos, los representantes americanos denunciaron los abusos que habían padecido y el estado miserable en que se hallaban tras de tres siglos de dominio español. De la misma forma actuó el diputado por la provincia de Chiapas, Mariano Robles y Domínguez, ${ }^{14}$ quien en su Memoria histórica de Chiapas presentada a las Cortes de Cádiz en mayo de 1813 informaba de la situación indígena:

La miseria en que vivían y viven, es extremada: pues apenas moran en sus pueblos, y más bien se les podía y puede considerar transeúntes, que no habitantes: sus alojamientos son unos ranchos o tristes chozas sin abrigo, y expuestas a la inclemencia [...]. En fin para colmo de su infelicidad viven toda la vida, llenos de agitación, y en continuo terror y sobresalto; porque llega a tal grado el desprecio y odio, con que se les trata, que no hay cochero, lacayo, ni hombre ruin [...] que no se crea autorizado para maltratarles públicamente, en vista del mal ejemplo y de la suma crueldad con que les tratan especialmente otras personas de carácter, y de superior esfera, azotándoles y dándoles de bofetadas o palos (Robles, 1813: 39-40).

Si bien era cierto que para ese momento los indios se hallaban en una situación decadente, esto no era su culpa; se debía al estado en que las autoridades coloniales los habían mantenido dado que "cuando las leyes no tienen aquella exacta y debida observancia que se propuso en su sancion el legislador; que cuando los ejecutores de ellas, lejos de llevarlas a efecto, son los primeros infractores, exasperan los pueblos y los conducen a su total ruina y exterminio". ${ }^{15}$
El discurso general consistía en que los indígenas no eran seres irracionales e incapaces. Para comprobarlo, los criollos recurrieron a las alabanzas del avance y progreso que las civilizaciones indígenas tenían a la llegada de los españoles, comprobados gracias a los vestigios que a la fecha se podían encontrar en América. Con ello confirmaban también el retroceso que dicha población había sufrido. Mariano Robles, por ejemplo, se encargó de ensalzar ante la asamblea gaditana la grandeza del sitio de Palenque descubierto desde el siglo XVI en la provincia chiapaneca.

En la sesión del 29 de mayo de 1813, el prelado habló del sitio arqueológico "reconocido" en 1787, con una extensión de "siete a ocho leguas de longitud (que seguramente no hay en el mundo ciudad que las tenga)" y con casas "de mampostería, de mucha capacidad, adornadas por dentro y fuera de varias figuras de estuco y de piedra de alto y bajo relieve". Esculturas que manifestaban la forma en que "se vestian y adornaban los principales indios, los guerreros, los caciques y los sacerdotes", por lo que se sabía que tenían una sociedad estratificada. En esta ciudad había también "adoratorios" o templos "entre los cuales se encuentra una cruz de piedra perfectamente labrada", así como "varias inscripciones con los caracteres de que usaban aquellos indios para manifestar sus ideas y pensamientos", es decir, que aquella civilización tenía el conocimiento de una escritura "a manera que nosotros lo hacemos".

Finalmente la batalla fue ganada por los americanos. En la Constitución de Cádiz, promulgada el 19 de marzo de 1812, se consideraba como ciudadanos a todos "aquellos españoles que por ambas lineas traen su origen de los dominios españoles de ambos hemisferios" y que se avecinen en cualquiera de los pueblos del Imperio. ${ }^{16}$

Antes y después de la promulgación de la Constitución, los diputados en Cádiz legislaron sobre varios aspectos que concernían a la población autóctona con la finalidad de que el indio se convirtiera en un ciudadano hecho y derecho. El 13 de marzo de 1811, las 
Cortes volvieron a decretar la abolición del tributo, que ya había sido derogado por la Regencia el 26 de mayo de 1810 y por el virrey de la Nueva España, Francisco Xaver Venegas, en octubre del mismo año. Era ésta una reforma indispensable para la asimilación de los indígenas a la sociedad puesto que dicha obligación exigía la permanencia de su estatus particular y modo de vida distinto (Rieu-Millan, 1990). ${ }^{17}$

Esta supresión no fue bien recibida por las autoridades americanas, que enviaron múltiples oficios, pues el tributo constituía una porción importante de la hacienda pública, indispensable para mantener el sistema administrativo y la lucha contra la insurgencia. A pesar de ello, las Cortes no permitieron su restablecimiento. La igualdad del indio y del español implicaba que el primero tendría la obligación de pagar las mismas contribuciones que el segundo, como la alcabala o el diezmo (Rieu-Millan, 1990).

Las medidas tomadas por las autoridades coloniales revelan claramente que la abolición del tributo no puso fin al vasallaje indígena, de ahí que las Cortes tuvieran que tomar otras medidas para terminar con éste. El siguiente paso fue abolir los repartimientos o mitas, así como los servicios personales de los indios, siendo el 14 de abril de 1812 cuando el diputado Castillo presentó ante el pleno esta proposición argumentando que "los indios son libres; y se ataca directamente su libertad individual obligándolos a trabajar contra su voluntad en obras ajenas". ${ }^{18}$ No debía obligarse a los indígenas a laborar en la parroquia, en las minas o en las haciendas de otros cuando debían ocuparse en el cultivo de sus tierras, produciendo para su beneficio.

Estas obligaciones para la población indígena fueron suspendidas mediante el decreto del 9 de noviembre del mismo año, con la finalidad de "remover todos los obstáculos que impidan el uso y el ejercicio de la libertad civil de los españoles de ultramar" y de "promover todos los medios de fomentar la agricultura, industria y la población". ${ }^{19}$ Además de la abolición de la mita, los servicios parroquiales y los trabajos en obras públicas, dicho decreto estipuló:

Se repartirán tierras a los indios que sean casados o mayores de 25 años, fuera de la patria potestad, de las inmediatas a los pueblos que no sean de dominio particular o de comunidades; mas si las tierras de comunidades fuesen muy cuantiosas con respecto a la población del pueblo a que pertenecen, se repartirá cuando más hasta la mitad de las tierras $[\ldots]^{20}$

El segundo decreto emitido por las Cortes con referencia al reparto agrario fue el del 4 de enero de 1813. Éste apareció "considerando que la reducción de los terrenos comunes a dominio particular, es una de las providencias que más imperiosamente reclaman el bien de los pueblos y el fenómeno de la agricultura e industria”. Esta orden estipuló que se redujeran a "propiedad particular", ya no las tierras ejidales pertenecientes a los pueblos, sino también los terrenos baldíos y realengos. ${ }^{21}$ Dichas tierras se distribuirían "en clase de acotados" para su disfrute exclusivo y para que pudieran, los propietarios, "destinarlos al uso o cultivo que más le acomode” (Franco, 1986: 171-172). Este decreto refleja la urgencia que tenía la naciente clase política, desde entonces, de privatizar las tierras, es decir, de crear una clase de individuos propietarios, más que hacer referencia directa a la desamortización de las propiedades comunales que en el decreto se siguen respetando.

Además de la propiedad, la educación de los indios fue un tema de gran importancia para los diputados ultramarinos. Ésta y la catequesis eran la clave para obtener un hombre civilizado: la occidentalización del indígena y su sumisión, a partir de la religión y la lengua castellana. Es por ello que Antonio Larrazábal, el diputado por Guatemala, presentó el 14 de febrero de 1812 varias proposiciones al respecto. El representante solicitó que se instalaran en los pueblos de indios 
seminarios o escuelas en las que se enseñara la lengua castellana, a leer, a escribir y a contar, al tiempo que se les impartiera el catecismo. ${ }^{22}$

Larrazábal hizo esta petición partiendo de que "la educación es la primera base de las virtudes y de la pública felicidad de los pueblos; y el gobierno no sólo debe proporcionarla y velar sobre ella, sino conciliar el menor gravamen posible de los individuos del Estado con el socorro de sus necesidades". Sólo a través de la instrucción podría terminarse con la "ignorancia, que particularmente en los indios se halla tan radicada". ${ }^{23}$

El 13 de agosto de 1813, ante las Cortes, se expuso la representación de la provincia de Trujillo, Perú, en la que se solicitaba la suspensión de la ley que penalizaba con azotes o cárcel a los indios que no asistieran a la parroquia a tomar la doctrina. ${ }^{24}$ En septiembre, la comisión de ultramar presentó la resolución al respecto: se abolía la pena de azotes en toda la monarquía, inclusive para los criminales, que solamente podrían ser castigados con "presidio u obras públicas"; la prohibición se hizo extensiva a los establecimientos públicos, seminarios de educación y escuelas. Dada esta prohibición, "los párrocos de las provincias de ultramar no podrán valerse de ella, ni por modo de castigo para con los indios, el de corrección, ni en otra conformidad, cualquiera que sea", teniendo los obispos la obligación de supervisar que en sus diócesis no se cometieran estos abusos. ${ }^{25}$

La ruta que siguieron los diputados en Cádiz para que el indio se convirtiera en ciudadano fue, primero, establecer la igualdad de éste con respecto al resto de los individuos que formaban la sociedad, lo que implicó terminar con su estatus de menor de edad, por lo que debían ser suprimidas todas las obligaciones provenientes de su estatuto "privilegiado": el tributo, el repartimiento, la mita y los servicios parroquiales; también, la prohibición de los abusos que contra él cometían, sobre todo los párrocos, con los castigos empleados para "corregir" su comportamiento.
Finalmente, se le debía educar y castellanizar para que pudiera valerse por sí mismo.

Las solicitudes que los diputados chiapanecos hicieron en Cádiz iban también en este sentido. Mariano Robles hizo con respecto a la población indígena varias peticiones. La primera con referencia a la siembra de tabaco en Simojovel, ${ }^{26}$ ordenada por la dirección general de Estanco de Guatemala y para la que había sido destinado "un número crecido de indios" de dicha demarcación, quienes sufrieron el maltrato abusivo del factor ${ }^{27}$ de Ciudad Real y sus visitadores, provocando la huida de los indios "al monte", "el único medio que les quedaba para sacudir tan pesado yugo, de que resultaría no sólo el exterminio de aquellos pueblos, sino la dificultad de reducir al cristianismo a los gentiles". ${ }^{28}$ Por lo tanto, Robles pedía que a los indios de Simojovel no se les obligara a sembrar tabaco a cuenta de la factoría de Ciudad Real; que se les permitiera sembrar y cultivar libremente el tabaco para sí, que sólo podrían vender a la factoría a precio equitativo; y que no se permitiera al factor, visitadores y demás dependientes de la renta ir a los pueblos indígenas.

Cuando presentó su Memoria histórica ante el pleno, solicitó también la concesión a los indios de doce becas sufragadas con los bienes propios de sus comunidades, que cubriesen la manutención, vestuario y docencia de dichos colegiales en el seminario conciliar de Ciudad Real de la provincia (Robles, 1813: 69). Pidió también encargar a los mercedarios calzados ${ }^{29}$ de Guatemala la conversión de los indios infieles llamados lacandones que habitaban las montañas aledañas a Palenque. ${ }^{30}$

El suplente de Mariano Robles en las Cortes, Fernando Antonio Dávila, ${ }^{31}$ no tuvo la oportunidad de hacer sus solicitudes ante el pleno dado el regreso de Fernando VII a España en 1814. Al recuperar el trono disolvió las Cortes y anuló todas las medidas adoptadas por ellas, así que el diputado Dávila se vio en la necesidad de hacer sus peticiones al Rey y al Consejo de Indias. ${ }^{32}$ Respecto al indio, propuso la reducción de los pueblos de indios que vivían dispersos 
en la montaña, previniendo que se formaran para ellos poblaciones, en especial para los moradores de Tila, Tumbalá y Chamula, y en otros sitios donde se hallaran situados en mayor número; para ello se utilizarían los fondos de comunidad y la cooperación de las familias reducidas; ${ }^{33}$ pidió que se ordenara a religiosos dominicos y franciscanos que se pusieran a la orden del obispo para realizar la tarea de evangelización de indios infieles y para ocupar los curatos vacantes; finalmente, solicitó que de ese momento en adelante todos los párrocos del obispado enseñaran la doctrina en lengua castellana, por considerar el conocimiento de las lenguas indígenas pobre, procurando que sus feligreses aprendiesen aquélla. ${ }^{34}$

En resumen, en cuanto al indio se refiere, ambos diputados hicieron peticiones similares encaminadas a la educación y asimilación cultural de la población indígena en la provincia. Esto obedeció, muy probablemente, a que ambos fueron religiosos cercanos al entonces obispo de Chiapas, Ambrosio Llano. ${ }^{35}$ De hecho, tanto Robles como Dávila le asistieron como secretarios particulares.

Todas las medidas y las peticiones de los diputados americanos -entre los que encontramos a los chiapanecos - estaban encaminadas a terminar con la figura jurídica del indio. Esto se logró a través de la supresión del tributo, de los servicios personales, de la mita y de los castigos físicos para su "corrección". Además, se convino en la repartición de tierras entre ellos, medio indispensable para convertirlos en propietarios individuales.

Estos cambios también eliminaban las repúblicas de indios a la par que se creaba el ayuntamiento constitucional. Una vez promulgada la Constitución de Cádiz se estableció que el "gobierno interior" de los pueblos debía estar a cargo de un ayuntamiento compuesto de alcaldes, regidores y un síndico procurador, siempre presidido por el jefe político, siendo estos puestos de elección popular y constituidos de acuerdo a la configuración del vecindario. ${ }^{36}$
Los ayuntamientos se instalarían "en los pueblos que no tengan, y en que convengan le haya" siempre y cuando contaran con una población mayor a mil "almas". Por lo tanto, aquellas repúblicas de indios que tuvieran la población necesaria pasarían a ser ayuntamientos constitucionales. Teóricamente este cambio supondría una ventaja más para los indígenas ya que se les estaba abriendo el camino a la igualdad en todos los sentidos.

\section{En Chiapas: que se "les haga trabajar [a los indios] con utilidad suya, y de la patria"}

Con el regreso de Fernando VII a España en 1814, el orden constitucional fue abolido, y todos los órganos de gobierno creados, la división de poderes y los decretos fueron suprimidos. Así, el monarca guardó bajo llave la Constitución y continuó gobernando como lo había hecho la dinastía borbónica hasta el momento de la invasión napoleónica. El indio volvió a su estatus "privilegiado" y de minoría de edad, siguió pagando el tributo y recibiendo el trato abusivo por parte de las autoridades coloniales que tanto se había denunciado en las Cortes.

En el periodo absolutista que va de 1814 a 1820, el único documento relativo a la situación indígena en Chiapas con que contamos es el Informe rendido por la Sociedad Económica de Ciudad Real. Sobre las ventajas y desventajas obtenidas con la implantación del sistema de intendencias, escrito en 1819. El texto trata de las desventajas de la instauración del sistema de intendencias en Chiapas a consecuencia de la desaparición de las dos alcaldías mayores y del repartimiento de mercancías ${ }^{37}$ que obligaba a los indios a trabajar.

El argumento era que si los indios por "naturaleza y carácter son indolentes y flojos", hacía falta "un agente a la vista que estimulado del propio interés como el que movía a los alcaldes mayores les haga trabajar con utilidad suya, y de la patria". ${ }^{38}$ Así, en este informe se describía a los indios como hombres perezosos que necesitaban que los vigilaran para trabajar. En 
contradicción ${ }^{39}$ con las ideas expresadas en las Cortes de Cádiz, donde se defendió a capa y espada su capacidad racional similar a la de cualquier español, en este discurso se siguió concibiendo al indígena como un menor de edad que requería de un pater familia para hacer lo que le correspondía, lo que suponía una ventaja para el propio indio, quien no era capaz siquiera de distinguir qué le convenía.

En el Informerendido por la Sociedad Económica de Ciudad Real, el indio era descrito como incapaz de saber qué le hacía bien y le convenía. Por lo tanto un tercero, con el estatus de hombre adulto, le demostraría el camino que habría de tomar y, en caso de no obedecer, podría ser castigado. Lo correcto era indicar al indígena el camino, siempre y cuando esto conllevara una mejora de la situación económica, la cual favorecería a todos los individuos de la sociedad, no solamente al sujeto implicado, en este caso el indígena.

\section{El indio debe "permanecer formando una nación realmente distinta"}

Tres años después de redactado el Informe rendido por la Sociedad de Económica de Ciudad Real, en la península se volvió a vivir una revolución..$^{40}$ Por ello se convocó nuevamente a Cortes, de tal forma que en cada provincia se tuvo que elegir nuevamente a un representante, para lo que la provincia chiapaneca volvió a designar a Fernando Antonio Dávila. En esta ocasión, el ayuntamiento de Ciudad Real entregó a su diputado unas instrucciones con varias peticiones para las cortes, una de las cuales era que se promoviera la colonización de la provincia por parte de españoles o extranjeros, pues "constituyendo los indios el mayor número de los habitantes de esta provincia exige la política cierto equilibrio entre ellos y los blancos". Se trataba de tierras situadas desde Bachajón, Tumbalá y Moyos hasta donde termina Tabasco, y desde la sierra de "Custepeque" hasta los pueblos situados en el Soconusco. La extensión de cada terreno sería de 300 varas $^{41}$ de frente y 400 de fondo, pudiendo ser comprados por los colonos. ${ }^{42}$

Para los miembros del ayuntamiento, los indios se consideraban a sí mismos una nación distinta de los españoles y, en realidad, lo eran: "sus costumbres, su idioma, vestido, alimentos, y hasta sus preocupaciones son diversas de los que se han distinguido hasta ahora con el nombre de españoles, siendo un fenómeno político que habiendo tantas castas en América no se haya confundido esta nación en el dilatado espacio de trescientos años".

Las diferencias de ideas y lenguaje entre españoles e indígenas eran "unas disposiciones hostiles" en la relación entre ambas naciones, siendo la indígena mucho mayor en la provincia, a proporción de un español por veinte indios, lo que había provocado que la nación dominante no pudiera vivir "sin precaución".

Los indios, hasta ese momento "por lo general han sido nulos para la buena o mala causa" política, adhiriéndose a una u otra causa según las circunstancias. Así se habían mostrado con la intromisión insurgente en Chiapas, cuando en los pueblos indígenas se condujeron "indiferentemente" ante las tropas de la provincia y las insurgentes, por tanto no se podía tener a los indígenas "ni por amigos ni por enemigos". De ahí que se preguntara el ayuntamiento: "iqué es lo que puede asegurarnos de no ser víctimas en lo futuro? Porque en la suposición de dos naciones diferentes igualmente civilizadas y viviendo en un mismo terreno icuál deberá ser la conducta de la más numerosa con respecto a la otra?"

La respuesta era sencilla, los indios debían "permanecer formando una nación realmente distinta hasta el punto de su civilización porque el tributo que pagan los clasifica esencialmente y éste lo deberán pagar hasta que saliendo a pasos contados de su barbarie se pongan al nivel de nosotros". El tributo no podía suspenderse porque en caso de ser igualados en la contribución a los españoles, ésta descansaría sobre el menor número de habitantes. Dado que los 
indios, a pesar de tener grandes extensiones de terreno para cultivar, cosechaban pequeñas cantidades, los impuestos que estos pagarían serían mínimos comparados con lo que hasta ese momento aportaban con el tributo.

También aseguraban que, a pesar de que los indios "tienen muchísimo terreno en [las comunidades] y que no permiten cultivar a ninguna otra casta", producían muy poco y seguían viviendo en la pobreza, como lo demostraba su forma de vida: "sus casas son unas chozas que apenas los defienden de la inclemencia, ni tienen muebles ni aun camas pues duermen en el suelo, y en las tierras frías se acuestan alrededor del fuego para calentarse".

Los repartimientos de las tierras comunales equilibrarían a la población, lo cual "acelerará la civilización de los Indios, allanará los caminos, auxiliará a los traficantes que ahora se hallan sin recursos en aquellos desiertos, desmontará unos terrenos cuya fertilidad se hace perjudicial por falta de cultivo".

De nuevo, las opiniones manifestadas en el texto son opuestas a las disposiciones de las Cortes de Cádiz. La igualdad del indio y el español, así como la abolición del tributo, fueron asuntos por los que los diputados pugnaron en el trienio liberal. Seis años después, los miembros del ayuntamiento de Ciudad Real peleaban por lo contrario. Era preciso mantener al indio en una nación diferente porque era incivilizado, porque constituía la mayor parte de la población, porque no se había mostrado como aliado de los españoles y, lo más importante, porque el tributo era indispensable para mantener el sistema de gobierno. Además, era necesario repartir las tierras comunales bajo su poder promoviendo con esto la llegada de población blanca a la provincia, lo que propiciaría la asimilación del indio.

El ayuntamiento se negaba a cambiar su estatus. Debía permanecer subordinado por la minoría blanca, sometimiento que aseguraba su control. Como puede apreciarse, esa sumisión no sólo convenía para garantizar el tributo, sino también por el miedo que tenían a una rebelión indígena dado el elevado número de su población.

\section{Consideraciones finales}

Las ideas de la ilustración que sostenían que la razón humana podía contribuir a la creación de un mundo mejor, tuvieron una gran influencia sobre aspectos económicos, políticos y sociales de la época, cambiando a su vez la forma de ver al indígena en Guatemala y Chiapas. La propuesta ilustrada respecto al indio, en cuanto a su integración a la sociedad se refiere, no estaba basada en una idea de sociedad multicultural en la que los distintos sectores de la misma pudieran vivir en armonía aceptando sus diferencias de idioma, costumbres y vestimenta. Se buscaba que el indígena se integrara a la sociedad en el momento en que dejara de ser diferente a lo que normaba la cultura occidental.

Estas ideas repercutieron en las Cortes de Cádiz. El reconocimiento del indio como un ciudadano más fue la más clara manifestación del interés por su desaparición desde las clases políticas. En este sentido fueron encaminados los decretos emitidos en Cádiz de 1810 a 1814: la igualdad ante la ley, la supresión de tributos, la eliminación de penas corporales, la desaparición de la mita y de los servicios personales, así como la creación de ayuntamientos constitucionales en pueblos indios. Entre las disposiciones de las Cortes también figuró la del repartimiento agrario entre los vecinos de los pueblos, lo que propiciaría el surgimiento de la clase propietaria. Jurídicamente se eliminó la figura del indio; se habían generado legalmente todas las condiciones para que éste fuera asimilado a la sociedad.

Años después, la Sociedad Económica vinculaba en su informe al indio con el trabajo: era el indígena indolente y flojo, incapaz de trabajar si no era forzado, por lo que era indispensable que alguien lo obligara a laborar por su bien y el de la provincia. No era igual a los españoles, 
no era racional, era un menor de edad. Dos años más tarde, el ayuntamiento de Ciudad Real manifestaba ampliamente su opinión al respecto: era indispensable promover la colonización de la provincia por españoles ya que el territorio estaba poblado mayoritariamente por indígenas. Como esta población era diferente en sus costumbres, lengua y preocupaciones, no podía ser igualada a la española; debía permanecer en una nación distinta y separada, y ello se debía no sólo a su incapacidad racional para ser asimilado a la sociedad, sino a la histórica relación hostil entre ambos grupos. Esta segunda preocupación proyecta también un profundo temor hacia el indio en Chiapas.

El tributo era una razón de peso para seguir manteniendo esta separación. Dicha contribución constituía un ingreso importante de los caudales públicos y su desaparición acarrearía la ruina financiera de la provincia, pues el pequeño número de españoles (12\% de la población) tendría la responsabilidad de mantener al aparato burocrático provincial.

Por lo tanto $-\mathrm{y}$ a pesar de todo lo acontecido en Cádiz-, el indio chiapaneco vislumbró la Independencia de la Nueva España sumido en la misma situación en la que vivió durante los trescientos años de dominio español.

\section{Notas}

${ }^{1}$ Informe que da el Gobernador e Intendente de Chiapa del Miserable estado que se hallan ala presente, los Partidos de la Intendencia de su Cargo, Y propone al mismo tiempo, los remedios y auxilios que pueden subministrársele para su incremento y beneficios, Ciudad Real, 1790, en AHCHBMOB (Archivo Histórico de Chiapas, Biblioteca Manuel Orozco y Berra) (INAH), tomo I, doc. 15.

${ }^{2}$ Ver nota 1.

${ }^{3}$ Informe del ayuntamiento de Ciudad Real del miserable estado en la que está la agricultura y de los vicios en que viven los naturales. Ciudad Real, 22 de enero de 1805, en AHCH-BMOB, tomo II, doc. 13, fs.l-lv.
${ }^{4}$ El problema del indio. Utilidad de que todos los indios y ladinos se vistan y calcen a la Española y medios de conseguirlo sin violencia, coacción ni maltrato, 1796, en Ateneo, año 1, vol. 2, abril-mayo-junio 1951, p. 17. Agradezco al Mtro. Mario Vázquez que me proporcionara este documento.

${ }^{5}$ El término "ladino" surge, en América Latina, al inicio de la época colonial para designar al indio que hablaba castellano a la perfección. "El castellano va a significar para el indio un instrumento de privilegio. Todo el que lo habla encuentra en la estructura colonial una ubicación que le permitirá escapar a la encomienda y al trabajo forzado. Ello creará un grupo social que a finales del siglo XVII se verá incorporado al sector denominado ladino. O sea, que la lengua, será, como la mezcla racial, un factor de mestizaje"; Ver Arturo Taracena Arriola, "Contribución al estudio del vocablo 'ladino' en Guatemala, (siglo XVI-XIX)", en Mestizaje, raza y Nación en Centroamérica: identidad tras conceptos, 1524-1950, Boletín No. 25, AFEHC, octubre de 2006. 〈http://ress.afehc. apinc.org/_articles/portada_afehc_articulos30.pdf> [17 de agosto de 2010].

${ }^{6}$ El problema del indio. Utilidad de que todos los indios y ladinos se vistan y calcen a la Española y medios de conseguirlo sin violencia, coacción ni maltrato, 1796, en Ateneo, año 1, vol. 2, abrilmayo-junio 195l, p. 17.

${ }^{7}$ Individuos indígenas que ostentaban la autoridad en las comunidades indígenas.

${ }^{8}$ Agradezco los comentarios al respecto del Dr. José María Portillo.

${ }^{9}$ Cuerpo legislativo medieval del principado presidido y convocado por el rey, compuesto por los tres órdenes o estamentos del Estado: el clero, la nobleza y el pueblo. Ver, Diccionario de la lengua castellana compuesto por la real academia española [en línea], Madrid, D. Joaquín Ibarra impresor de cámara de S.M. y de la Real Academia, 1783, 〈http://buscon.rae.es/ntlle/SrvltGUIMenuNtll e?cmd=Lema\&sec=1.0.0.0.0> [22 de junio de 2010]. La convocatoria se hizo por estamentos y su finalidad era "tratar en ellas primeramente de la conservación de nuestra santa religión católica" para intentar por todos 
los medios posibles la liberación del monarca español, "tomar las medidas eficaces a fin de continuar la guerra en que tan justa y gloriosamente se halla empeñada la Nación" y para "restablecer y mejorar la constitución fundamental" de los reinos en la cual se afianzarían los derechos a la soberanía de Fernando VII.

${ }^{10}$ Clase impartida por el Dr. José María Portillo en el curso de Historia de España del Instituto de Investigaciones Históricas en la Casa de las Humanidades el día 4 de mayo de 2010.

11 Decreto V. Igualdad de derechos entre españoles europeos y ultramarinos, 15 de octubre de 1810, en Colección de los decretos y órdenes que han expedido las Cortes Generales y Extraordinarias desde su instalación en 24 de septiembre de 1810 hasta igual fecha de 1811, en 〈http:// www.cervantesvirtual.com/servlet/SirveObras/ hist/01604630436704913000035/ima0025.htm> [31 de mayo 2010].

${ }^{12}$ Diarios de sesiones de las Cortes generales y extraordinarias, 23 de enero de 1811, en Cobá, (2006: 44) y en Rieu-Millan, (1990: 111).

13 Representación de los diputados del Reino de Guatemala, Cádiz, 1812, en CEM (Centro de Estudios Mayas, Universidad Nacional Autónoma de México), fondo AGI, Rollo 38, Guatemala 417, Audiencia de Guatemala.

${ }^{14}$ Originario de Ciudad Real de Chiapas y proveniente de una familia de la élite, fue ordenado presbítero en Nueva Guatemala en 1796. Ocupó la canonjía de merced de la catedral de Ciudad Real en 181l, convirtiéndose en el secretario particular del obispo Ambrosio Llano. En 1811 fue electo diputado a las Cortes tras la muerte del primer diputado electo por la provincia, Sebastián Esponda, miembro del ayuntamiento de Ciudad Real. Arribó a las Cortes en septiembre de 1812, donde permaneció hasta 1814. Fue miembro fundador de la Sociedad de Amigos del País de Ciudad Real, y en 1819 provisor del obispado y vicario general. Un año después fue electo representante de Chiapas ante la Diputación provincial de Guatemala. En 1825 fue designado rector del seminario y deán del cabildo eclesiástico cinco años después fue electo senador por el estado de Chiapas. Murió en 1832 en Puebla víctima del cólera. Ver, Vázquez y Torres (2010: 73); Esponda (2004: 25-29); Diccionario, en Asociación para el Fomento de los Estudios Históricos de Centroamérica [en línea], 〈http://afehc-historia-centroamericana. org/index.php?action=fi_aff\&eid=727> [1 de junio de 1810]; Elección y sorteo practicado por este noble Ayuntamiento el día 4 de noviembre de 1811 para diputado en Cortes por el que salió en sus suerte el señor presbítero Don Mariano Robles, secretario del ilustrísimo Señor Obispo de esta Diócesis, Ciudad Real, 4 de noviembre de 181l, en AGI, Indiferente, Leg. 1523. Agradezco al Mtro. Mario Vázquez el acceso a dicho documento.

${ }^{15}$ Sesión de las cortes del 29 de mayo de 1813, en Diario de sesiones ordinarias y extraordinarias de cortes, [CD ROM], 2005, s.e.

${ }^{16}$ Constitución política de la Monarquía Española: Promulgada en Cádiz á 19 de Marzo de 1812 (Precedida de un Discurso preliminar leído en las Cortes al presentar la Comisión de Constitución el proyecto de ella), Alicante, Biblioteca Virtual Miguel de Cervantes; Madrid, Biblioteca Nacional, 2004, pp. 8-9, en 〈http://www.cervantesvirtual.com/FichaObra. html?Ref=12837\&portal=56> [31 de mayo de 2010].

${ }^{17}$ Colección de los decretos y órdenes que han expedido las Cortes Generales y Extraordinarias desde su instalación en 24 de septiembre de 1810 hasta igual fecha de 1811, en Biblioteca Virtual Miguel de Cervantes [en línea], http://www.cervantesvirtual.com/servlet/ SirveObras/01604630436704913000035/index.htm>. [Consulta 31 de mayo de 2010]; Real orden de 26 de mayo de 1810; publicada en bando de 5 de octubre del mismo año, libertando de tributo a los indios, Isla de León, 26 de mayo de 1810, en Legislación mexicana de Manuel Dublán y José María Lozano [CD], Suprema Corte de Justicia de la Nación/ Tribunal Superior de Justicia del Estado de México-COLMEX-Escuela 
Libre de Derecho, 2004, t. I, pp. 331-332; (Pollack, 2008: 87).

${ }^{18}$ Sesión de cortes del 29 de mayo de 1813, en Diario de sesiones ordinarias y extraordinarias de cortes, documento en línea citado.

${ }^{19}$ Colección de los decretos y órdenes que han expedido las Cortes Generales y Extraordinarias desde su instalación en 24 de mayo de 1812 hasta 24 de febrero de 1813, t.III, en Biblioteca Virtual Miguel de Cervantes, en <http://www.cervantesvirtual.com/servlet/ SirveObras/35772796767144497754491/index.htm> [31 de mayo de 2010].

${ }^{20}$ Sesión de Cortes del 4 de enero de 1813, en Diario de sesiones ordinarias y extraordinarias de cortes, documento en línea citado.

${ }^{21}$ Los terrenos realengos eran los pertenecientes a la monarquía.

${ }^{22}$ Medio extraordinario que se propone para el logro de algún fin.

${ }^{23}$ Sesión de Cortes de 14 de febrero de 1813, en Diario de sesiones de las Cortes Generales y Extraordinarias, documento en línea citado.

${ }^{24}$ Sesión de Cortes del 13 de agosto de 1813, en Diario de sesiones de las Cortes Generales y Extraordinarias, documento en línea citado.

25 "Decreto de las Cortes españolas", en Campana Chiapaneca, tomo I, núm. 6, 10 de junio de 1827, p. 13.

26 Ésta se realizaba a modo de repartimiento de mercancías.

${ }^{27}$ Comerciante, apoderado con mandato extenso para traficar en nombre y por cuenta del poderdante o para auxiliarle en los negocios.

${ }^{28}$ Sesión de Cortes del 14 de diciembre de 1812, en Diario de sesiones de las Cortes Generales y Extraordinarias, documento en línea citado.

${ }^{29}$ Religiosos pertenecientes al convento de la Merced.

${ }^{30}$ A pesar de que se había ordenado a los dominicos la evangelización de los indios infieles, no se había hecho nada al respecto pues estos religiosos eran pocos en la provincia.
${ }^{31}$ Nació en 1783, en la parroquia de San José de la Antigua Guatemala, miembro de una familia de la élite guatemalteca de rango subalterno. Realizó sus estudios en la Universidad de San Carlos y se mudó a Ciudad Real como profesor del colegio seminario. En 1813 era cura de la parroquia de Tila en la provincia de Chiapas, donde se convirtió en secretario particular del obispo Ambrosio Llano, quien se refugiara en ese pueblo tras la entrada de la insurgencia novohispana en la provincia bajo el mando de Mariano Matamoros. Es muy probable que a esto se debiera que la elección para diputado a Cortes recayera en él. En 1815 laboró como cura vicario rector del sagrario de la catedral de Ciudad Real y posteriormente fue miembro fundador de la Sociedad de Amigos del País de Ciudad Real. Para el periodo en Cortes de 1820-1821, fue elegido nuevamente representante de la provincia. Tras la independencia de Chiapas regresó a Guatemala donde participó activamente en la política y en donde vivió hasta su muerte en 1846. Ver Diccionario, en Asociación para el Fomento de los Estudios Históricos de Centroamérica, 〈http://afehc-historia-centroamericana.org/index. php?action=fi_aff\& $\&$ id=625> [ 1 de junio de 2010].

${ }^{32}$ Carta de Fernando Antonio Dávila a Ambrosio Llano, Campeche, 11 de diciembre de 1815, en AHD (Archivo Histórico Diocesano, San Cristóbal de Las Casas), Correspondencia de Ambrosio Llano.

${ }^{33}$ Solicitudes del diputado de la provincia de Chiapas Fernando Antonio Dávila, Madrid, 1814, en CEM, Fondo AGI, Rollo 38, Guatemala 423, Audiencia de Guatemala.

${ }^{34}$ Solicitudes del diputado Fernando Antonio Dávila, 12 de junio de 1814, en CEM, Fondo AGI, Rollo 38, Guatemala 423, Audiencia de Guatemala.

${ }^{35}$ Nació en la Villa de Rueda, Valladolid, España, el 7 de diciembre de 1746. Estudió en la Universidad de Valladolid filosofía, teología y derecho, recibiendo el grado de bachiller. Posteriormente estudió en el Gimnasio y a continuación fue nombrado provisor de la catedral de Guatemala por Cayetano Francisco 
de Monroy, arzobispo electo de Guatemala. En dicha ciudad adquirió el puesto de vicario general, en el que trabajó durante 22 años. Con la muerte de don Fermín José Fuero, quien fuera obispo de Ciudad Real, Ambrosio Llano fue electo obispo de dicha ciudad el 25 de febrero de 1801. Tomó posesión del cargo el 23 de septiembre de 1802, y en 1809 tomó el puesto de intendente interno de la provincia tras ser expulsado el entonces intendente José Mariano Valero por el ayuntamiento de Ciudad Real. Murió el 27 de julio de 1815 en el pueblo de Tila. Ver. Documentos del Obispo Ambrosio Llano, en AHD (Archivo Histórico Diocesano, San Cristóbal de Las Casas), (Polushin, 2004: 291-317).

${ }^{36}$ Constitución de Cádiz de 1812, Cádiz, 18 de marzo de 1812, en Biblioteca Virtual Miguel de Cervantes [el línea], 〈http://www.cervantesvirtual.com/servlet/ SirveObras/02438387547132507754491/p0000001. htm\#I_35_> [17 de agosto de 2010].

37 El repartimiento de mercancías consistía en el intercambio de productos agrícolas y otros artículos a partir de su colocación en varios poblados por parte del alcalde mayor, asegurando que los productos circularan al interior de la provincia. El alcalde, por tanto, decidía qué debían comprar o vender cada una de las comunidades indígenas y fijaba el precio. Las ganancias de estos productos eran el pago del funcionario. Ver Carvalho (1994: 35).

${ }^{38}$ Informe rendido por la Sociedad Económica de Ciudad Real sobre las ventajas y desventajas obtenidas con el establecimiento del sistema de intendencias, Ciudad Real, 1819, en Boletín de Documentos históricos de Chiapas, núm. 5, año 3, julio-agosto de 1955, p. 100.

${ }^{39}$ Esta contradicción puede ser agravada por el hecho de que el documento fuera firmado por los dos exdiputados a Cortes por la provincia de Chiapas, Mariano Robles y Fernando Antonio Dávila.

${ }^{40}$ Como ya se dijo, en 1814 Fernando VII obtuvo nuevamente la soberanía debido a que un grupo de la sociedad hispana (los serviles) vio sus fueros y privilegios en peligro. Por lo tanto, el monarca se vio comprometido con este grupo y en la imposibilidad de gobernar con todos los poderes que sus antepasados habían tenido. Este compromiso imposibilitó mover la maquinaria estatal libremente durante el sexenio fernandino, provocando la aceleración de la decadencia del imperio causada por la crisis en que se hallaban las arcas públicas. Aunado a esto, la insurgencia americana se fortalecía y se había formado una guerrilla dispersa en la península contraria al orden establecido. La crisis alcanzó al ejército real. Fue por ello que en 1820 una parte del mismo, acantonada en Cabeza de San Juan para salir a combatir a la insurgencia sudamericana y liderada por Rafael de Riego, se pronunció por el restablecimiento del orden constitucional. Otros regimientos se manifestaron a favor de la Constitución y, poco tiempo después, toda la península. Fernando VII se vio obligado a jurar la Constitución y a restablecer los órganos de gobierno liberales (Ávila, 2002: 183-184).

${ }^{41}$ Una vara equivalía a $0.9144 \mathrm{~m}$.

${ }^{42}$ Instrucciones para el Sr. diputado en Cortes de Chiapas dadas por el Ayuntamiento de Ciudad Real, Ciudad Real, 30 de octubre de 1820, en AHCH-BMOB, tomo III, doc. 2.

\section{Bibliografía}

Aquino Juan, Jesús y Arturo Corzo Gamboa (1994), La Independencia de Chiapas y sus anexiones a México (18211824), Tuxtla Gutiérrez: Universidad Autónoma de Chiapas.

Ávila, Alfredo (2002), En nombre de la Nación. La formación del gobierno representativo en México, México: Taurus/ CIDE.

Bonilla Bonilla, Adolfo (1999), Ideas económicas en la Centroamérica ilustrada. 1793-1838, El Salvador: FLACSO El Salvador.

Campillo y Cosío, José del (1789), Nuevo sistema de gobierno económico para América. Con los males y daños que le causa el que hoy tiene, de los que participa copiosamente España; y 
remedios universales para que la primera tenga considerable ventajas, y la segunda mayores intereses, Madrid: Imprenta de Benito Cano.

Carvalho, Alma Margarita (1994), La Ilustración del Despotismo en Chiapas, 1774-1821, México: Consejo Nacional para la Cultura y las Artes.

Clavero, Bartolomé (1994), Derecho indígena y cultura constitucional en América, México: Siglo XXI.

Clavero, Bartolomé (2000), Ama llunku, abyayala. Constituyencia indígena y código ladino por América, Madrid: Centro de Estudios Políticos y Constitucionales.

Clavero, Bartolomé (2007), El orden de los poderes. Historia constituyente de la trinidad constitucional, Madrid: Editorial Trotta.

Clavero, Bartolomé (2010), "Constitución de Cádiz y ciudadanía de México" en Garriga, Carlos (coord.), Historia y Constitución. Trayectos del constitucionalismo hispano, México: CIDE/ Instituto Mora/ El Colegio de Michoacán/ELD/ HICOES/ El Colegio de México, pp. 141-172.

Cobá Noh, Lorgio (2006), "De la minoría a la mayoría de edad política: el estatuto legal del indio en la coyuntura liberal, 1810-1814", en Melchor Ocampo García (ed.), Entornos del "ciudadanato" en Yucatán, 17501906, Mérida: Universidad Autónoma de Yucatán, pp. 27-72.

CobáNoh, Lorgio (2009), El “indio Ciudadano". La tributación y la contribución personal directa en Yucatán, 1786-1825, México: Instituto Mora/Universidad Autónoma de Yucatán. Constitución del Estado de Chiapas. Sancionadapor su congreso constituyente en 19 de noviembre de 1825 (1826), Villahermosa: Impresa por el C. José M. Corrales.

Esponda Jimeno, Víctor Manuel (2004), "Mariano Nicolás Robles de Mazariegos y Domínguez en las Cortes de Cádiz 1813", en Aguirre Moreno, María Teresa et al., Ciudad Real, España. San Cristóbal de Las Casas, Chiapas 1528-2003, San Cristóbal de Las Casas: Seminario de Cultura Mexicana corresponsalía San Cristóbal de Las Casas.
Fernner, Justus (2005), "Fuentes primarias para el Chiapas decimonónico", en Olivera, Mercedes y María Dolores Palomo (coord.), Chiapas: de la Independencia a la Revolución, México: Publicaciones Casa Chata, pp. 385-436.

Franco Mendoza, Moisés (1986), "La desamortización de bienes en comunidades indígenas en Michoacán", en Carrasco, Pedro et al., La sociedad indígena en el Centro y Occidente, Zamora Michoacán: El Colegio de Michoacán, pp. 169-188.

Gerhard, Peter (1991), La frontera sureste de la Nueva España, México, Universidad Nacional Autónoma de México. Hale, Charles (2005), El liberalismo mexicano en la época de Mora (1821-1853), México: Siglo XXI.

Martínez, Severo (1998), La patria del criollo, México: Fondo de Cultura Económica.

Martínez Mendoza, Sarelly (2004), La prensa maniatada. El periodismo en Chiapas de 1827 a 1958, México: Fundación Manuel Buendía/Gobierno del Estado de Chiapas.

Ortiz Herrera, Rocío (2003), Pueblos indios, Iglesia católica y élites políticas en Chiapas (1824-1901). Una perspectiva comparativa, Tuxtla Gutiérrez: Consejo Estatal para la Cultura y las Artes de Chiapas.

Pérez Salas, Esther y Diana Guillén (1994), Chiapas, una historia compartida, México: Instituto Mora.

Pollack, Aaron (2008), Levantamiento k'iche en Totonicapán, 1820. Los lugares de las políticas subalternas, Guatemala: AVANCSO.

Polushin, Michael A. (2004), “Por la Patria, el Estado y la Religión': la expulsión del intendente accidente de Ciudad Real, Chiapas (1809)", en Ibarra, Ana Carolina (coord.), La independencia en el sur de México, México: Universidad Nacional Autónoma de México, pp. 291-317.

Portillo Valdés, José María (2006), Crisis atlántica. Autonomía e independencia en la crisis de la monarquía hispana, Madrid: Fundación Carolina/Centro de Estudios Hispánicos e Iberoamericanos/Marcial Pons Historia. 
Rieu-Millán, Marie Laure (1990), Los diputados americanos en las Cortes de Cádiz, Madrid: Consejo Superior de Investigaciones Científicas.

Robles Domínguez de Mazariegos, Mariano (1813), Memoria histórica de la provincia de Chiapas, una de las de Guatemala, Cádiz: Imprenta Tormentaria a cargo de D. J. D. Villegas.

Rodríguez, Mario (1984), El experimento de Cádiz en Centroamérica 1808-1826, México, Fondo de Cultura Económica.

Ruiz Abreu, Carlos (Coord.) (1994), Historia del H. Congreso del estado de Chiapas, 3 vol, Tuxtla Gutiérrez: Gobierno del Estado de Chiapas/Congreso LVIII Legislatura.

Tanck de Estrada, Dorothy (2005), Atlas ilustrado de los pueblos indios. Nueva España, 1800, México: El Colegio de México/El Colegio Mexiquense/Comisión Nacional para el Desarrollo de los Pueblos Indígenas/Fomento Cultural Banamex.

Torres Freyermuth, Amanda Úrsula (2008), "Trabajo (indígena), control y castigo. La ley de servicios chiapaneca de 1827", en tesina de licenciatura en Historia, México: Universidad Nacional Autónoma de México.

Trens, Manuel B. (1942), Historia de Chiapas. Desde los tiempos más remotos hasta el gobierno del general Carlos A. Vidal, México: La Impresora.

Vázquez Olivera, Mario (2001), "La cuestión de Chiapas en la prensa mexicana, 1823-1824", en Castro, Miguel Ángel, Tipos y caracteres. La prensa en México de 1821 a 1855, México: Instituto de Investigaciones Bibliográficas/ Universidad Nacional Autónoma de México.

Vázquez Olivera, Mario (2003), "Chiapas entre Centroamérica y México, 1821-1826”, en Vázquez, Josefina Zoraida (coord.), El establecimiento del federalismo en México (1812-1827), México: El Colegio de México, pp. 583-607.
Vázquez Olivera, Mario (2005), “Chiapas, Centroamérica y México, (1821-1841). Nuevos elementos sobre una antigua discusión", en Olivera, Mercedes y María Dolores Palomo (coord.), Chiapas: de la Independencia a la Revolución, México: Publicaciones Casa Chata, pp. 53-72.

Vázquez Olivera, Mario (2007), "Trazos de historia política. El estado de Chiapas y la federación mexicana, 1824-1835", en Anuario 2006, Tuxtla Gutiérrez: Centro de Estudios de México y Centroamérica-Universidad de Ciencias y Artes de Chiapas, pp. 199-242.

Vázquez Olivera, Mario (2010), El Imperio mexicano y el Reino de Guatemala. Proyecto político y campaña militar, 1821-1823, México: Fondo de Cultura Económica/ Universidad Nacional Autónoma de México/ Centro de Estudios sobre América Latina y el Caribe.

Vázquez Olivera, Mario (2010), “Un remedio de antiguos atenienses'. Los ayuntamientos de Chiapas en la proclamación de la independencia y la unión a México", en Vázquez Olivera, Mario, Chiapas, años decisivos. Independencia, Unión a México y Primera república federal, en prensa, pp. 67-93.

Vázquez Olivera, Mario y Amanda Torres Freyermuth (2010), "La participación en las Cortes españolas y el despertar autonomista de Chiapas, 1813-1821”, en Mesoamérica, Plumsock Mesoamerican Studies, año 31, núm. 54, enero-diciembre, Saratoga Springs, pp. 62-86. Viqueira, Juan Pedro (2002), “Las causas de una rebelión india: Chiapas 1712", en Viqueira, Juan Pedro y Mario Humbreto Ruz (ed.), Chiapas. Los rumbos de otra historia, México: Universidad Nacional Autónoma de México/ Centro de Investigaciones y Estudios Superiores en Antropología Social, pp. 103-143.

Vos, Jan de (1997), Vivir en frontera. La experiencia de los indios en Chiapas, México, CIESAS/INI. 